تقييم الفعالية المضادة للأكسدة لمركب الكركمين النقي في الفئران البيض

\title{
Evaluation of antioxidant activity for pure curcumin in albino mice
}

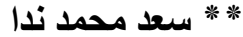

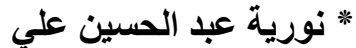 \\ لبيب احمد الزبيدي

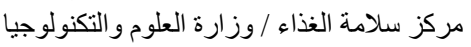

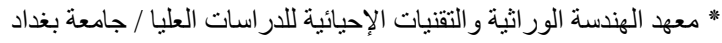

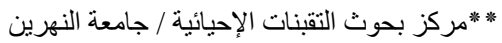 \\ Labeeb Ahmed Al-Zubaidi * Norrya Abdul-Hussein Ali * * $\quad$ *aad M. Nida \\ Food Safety Center, Ministry of Science and Technology/ Baghdad, Iraq \\ *Genetic Engineering and Biotechnology Institute for Post Graduate Studies/University of Baghdad \\ *** Biotechnology center/ University of Al- Nahrain,
}

أجريت الدراسة للكثف عن ألتأثير السمي والمؤكسد والمضاد للأكسدة لاحد مركبات نبات الكركم

، CCl مركب الكركمين النقي ومقارنته بفيتامين Curcrcuma longa

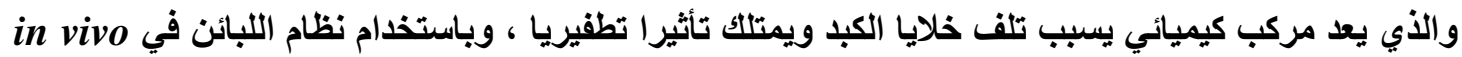

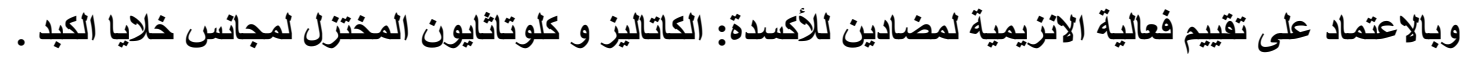

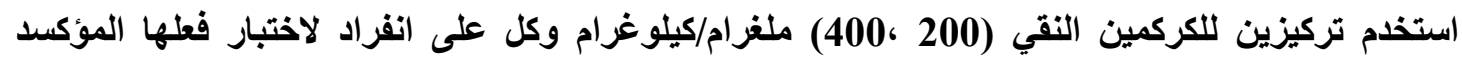

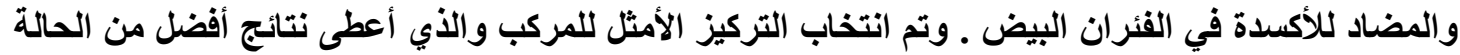

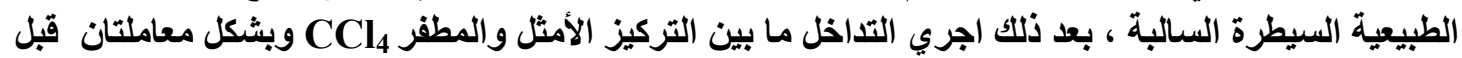

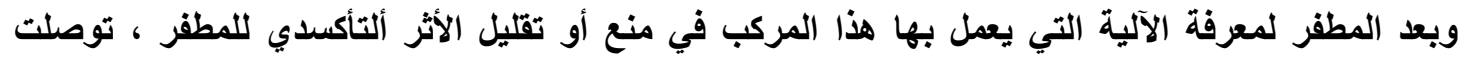

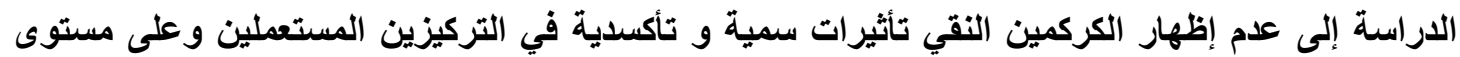

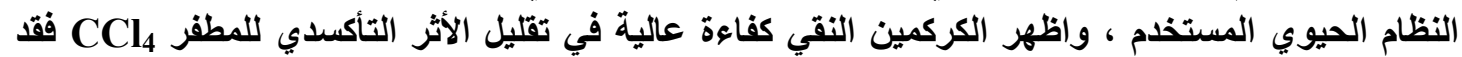

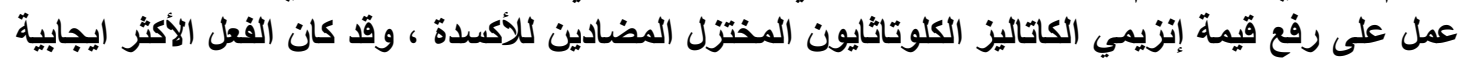

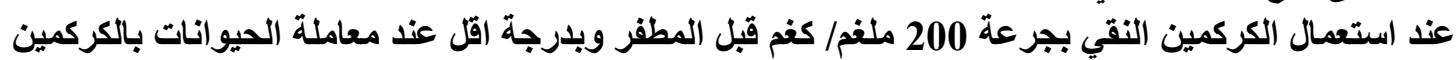

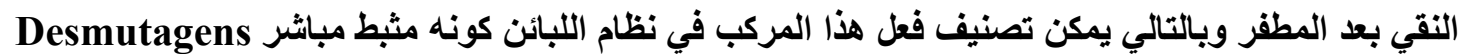
بالدرجة الأولى ومثبطات حيوية Bioantimutagens بالدرجة فئة الثانية .

Abstract

Q he study was carried out in order to determine the toxic, oxidant and antioxidant effects for one compounds of the Curcrcuma longa $\mathrm{L}$. in comparison with vitamin $C$ against the mutagenic effect of carbon tetrachloride $\mathrm{CCl}_{4}$, which is a chemical compound that damages hepatic cells and has mutagenic effects. The effect was studied in a mammalian system. This in vivo system depended on evaluating the enzymatic activity of two anti oxidant enzymes: Catalase and Glutathione reductase. Two concentrations of pure curcumin 200 and $400 \mathrm{mg} / \mathrm{kg}$ were evaluated to chose the suitable concentration, which remembered the negative control. In order be used in The interaction experiments, included two types of treatments pre $-\mathrm{CCl}_{4}$ and post- $\mathrm{CCl}_{4}$ in order to determine the mechanisms of the pure curcumin in preventing or reducing the antioxidant effect of $\mathrm{CCl}_{4}$. The pure curcumin showed no toxic and oxidant effects in biological system, and instead it showed highly performance in preventing or reducing the oxidant stress effects of $\mathrm{CCl}_{4}$. It increased the Catalase and Glutathione reductase antioxidant activity, especially in dose 200 $\mathrm{mg} / \mathrm{kg}$. The positive effect was higher when pure curcumin was used as $\mathbf{p r e - \mathrm { CCl } _ { 4 }}$ 
treatments, and to less extent in post- $\mathrm{CCl}_{4}$ treatment. Therefore, the plant extracts can be considered as adesmutagen at the first degree and a bioantimutagen at the second degree.

المقدمة

تمثل الأكسدة تفاعل كيميائي ينتقل فيه ألكترون من المادة إلى عامل مؤكسد ، ويمكن لتفاعلات التاكسدية أن تحرر

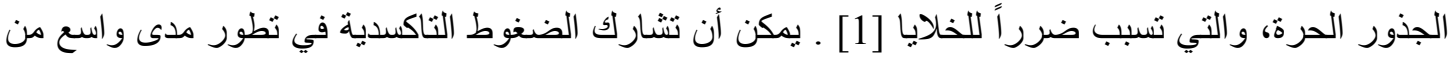

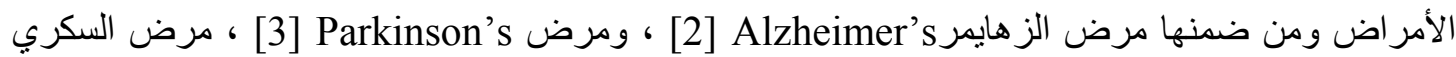

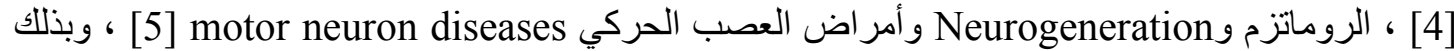

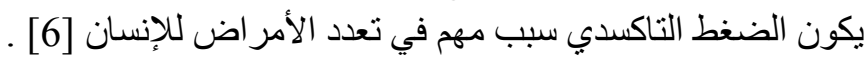

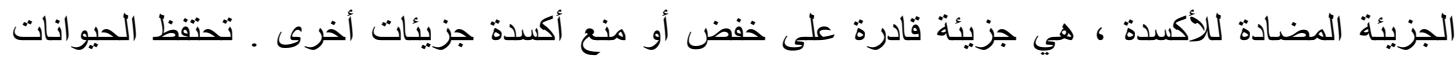

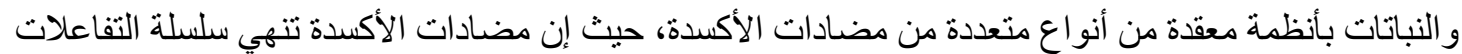

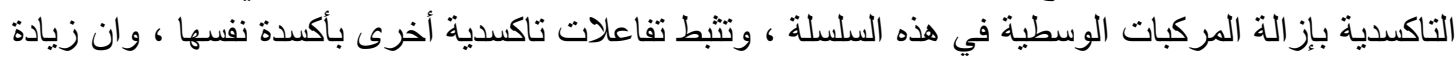

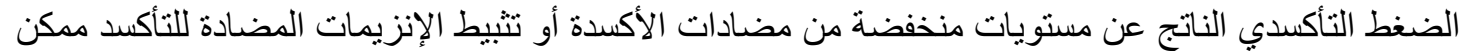

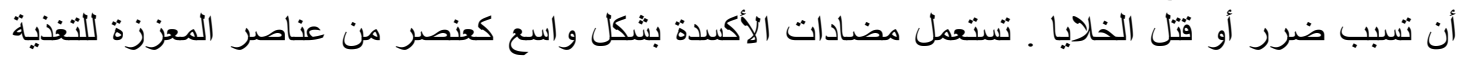

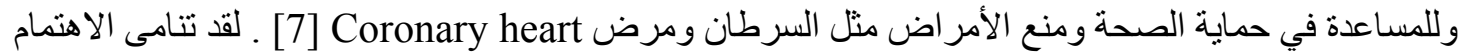

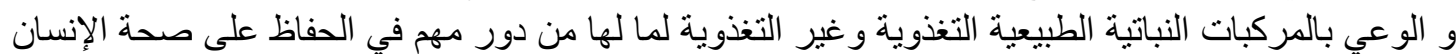

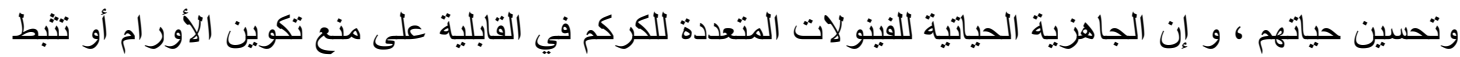

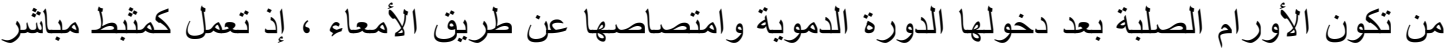

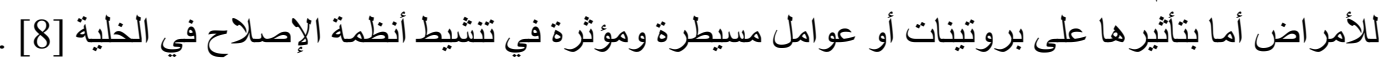

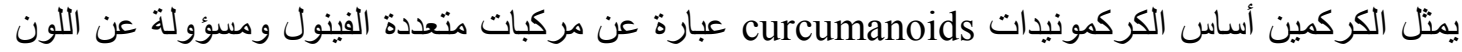
الأصفر للكركم في الكركم حيث يبلغ 75\% من معظم الكركمونيدات [9] ـ و الكركمين مركب متعدد الفينول غير

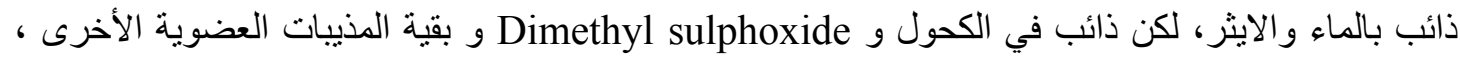

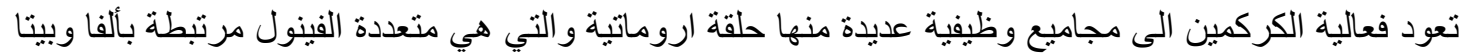

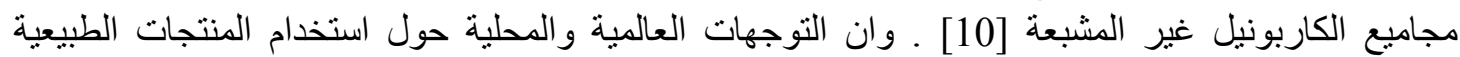
وخصوصا الأعثاب في المجالات العلاجية والطبية والغذائية قد جعلنا نوجه الدراسة الحالية لتقييم الفعالية

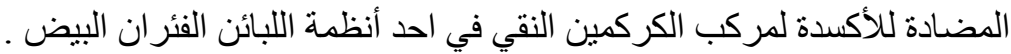

المواد وطر ائق العمل

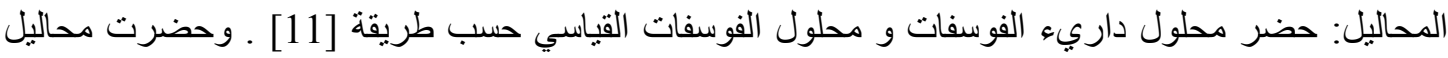

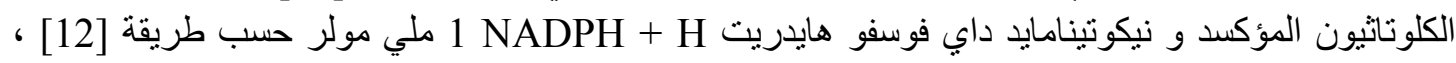
وحضر محلول بيروكسيد الهيدروجين المخفف بمزج 0.112 مليلتر من بيروكسيد الهيد الهيدروجين

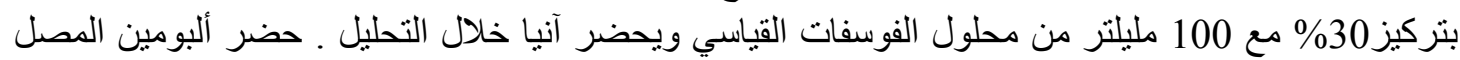
ألبقري [1\% Bovine Serum Albumin- BSA بإذابة 1 غرام من الـ BSA مي في 100 مليلتر من الماء المقطر المعقم ـ بينما ذوبت حبة واحدة (1 ملغرام) من الكولجسين في مليلتر واحد من الماء المقطر المعقم وحقن

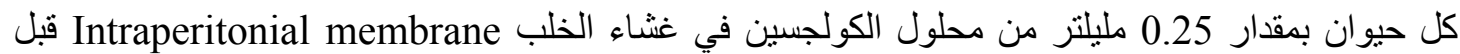

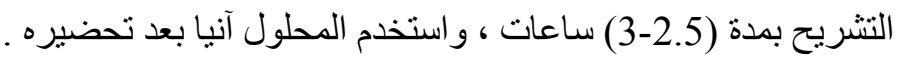

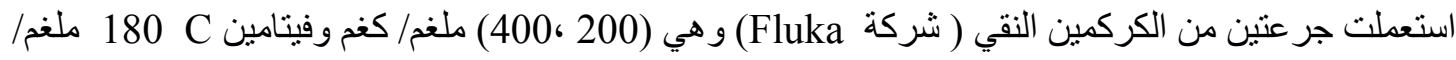
كغم كمجمو عة مقارنة ومركب المقطر كمجموعة سيطرة سالبة ، لدر اسة التأثثير التاكسدي والمضاد للأكسدة في الحيو انات المختبرية حيث كان

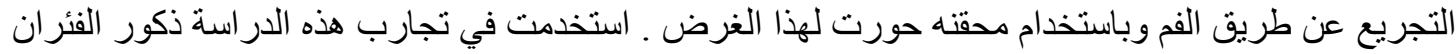

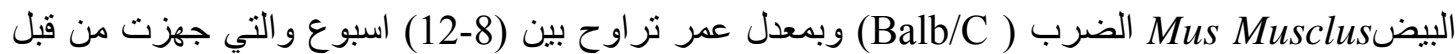

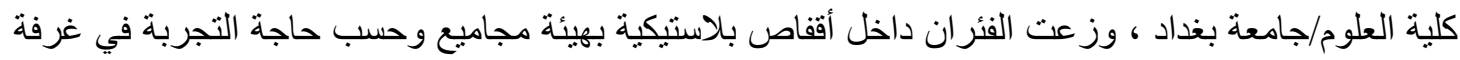
تر اوحت درجة الحر ارة فيها بين (23 و 25) م ، و وأعطيت هذه الحيو انات الماء و العليقة المتكاملة و المصنعة محليا

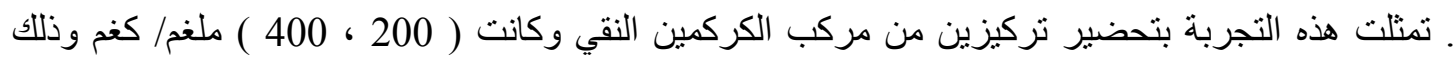


بإذابة 100 ملغر ام من مركب الكركمين النقي في 2 مليلتر PBS و و200 ملغم من الكركمين النقي في2 مليلتر

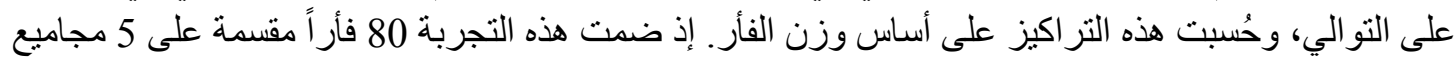

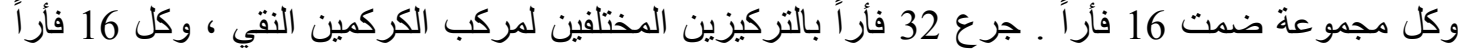

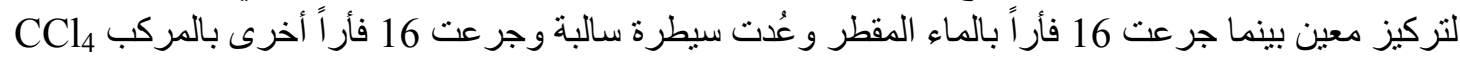

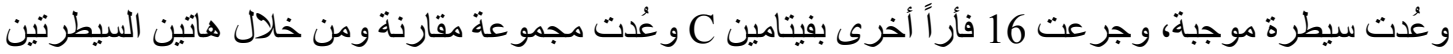
و المقارنة يمكن إعطاء فكرة أولية عن النركيز الأمثل لمركب الكركمين النقي وكانت كمية الجرعة 0.1 مليلتر

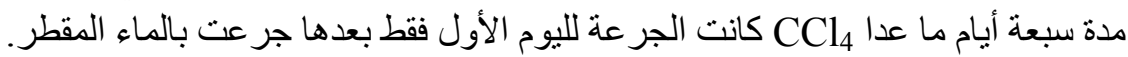

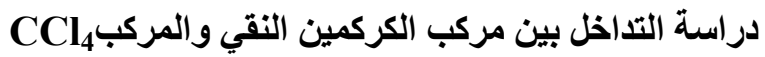

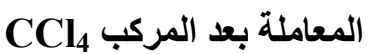

خصص لهذه التجربة 24 فأر اً منها ثمانية جرعت بـت بالتركيز الأمثل لمركب الكركمين النقي بتركيز 200 ملغر ام/

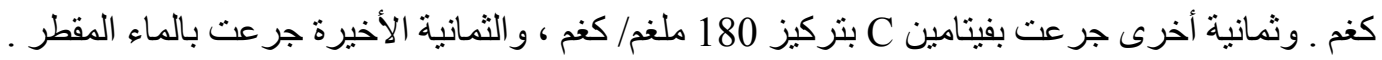

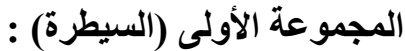
تم تجريعها بالمركب

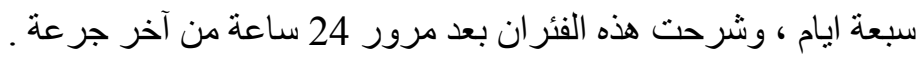
المجموعة الثانية (المقارنة):

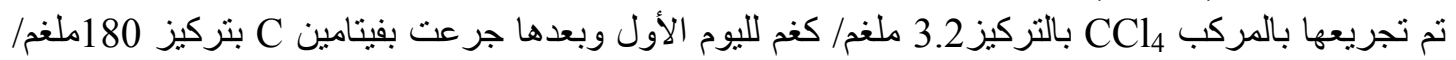

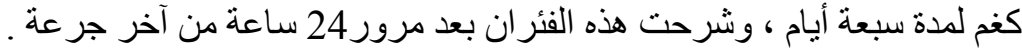

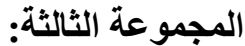

تم تجريعها بالمركب CCl $\mathrm{CCl}_{4}$ بالتركيز 3.2 ملغم/ كغم لليوم الأول بعدها تم تجريعها بالتركيز الأمثل لمركب

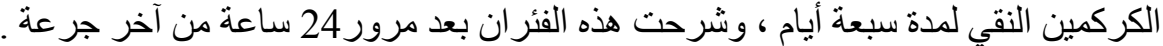

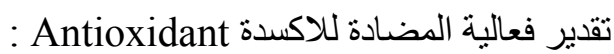
تحضير المستخلص النسيجي :

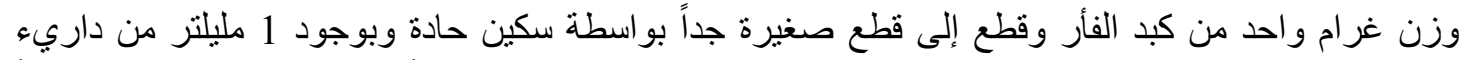

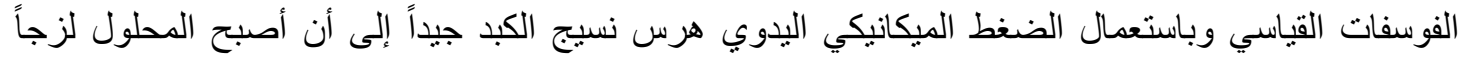

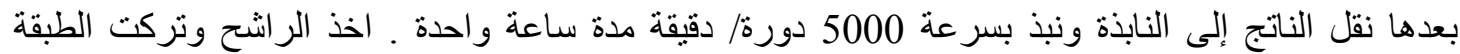

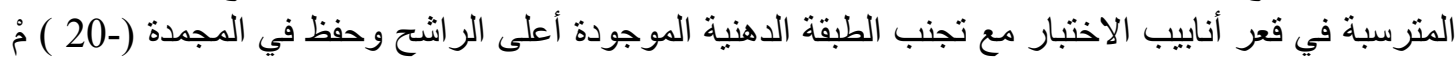

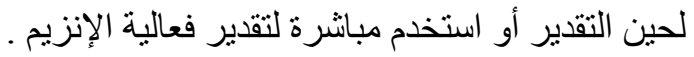

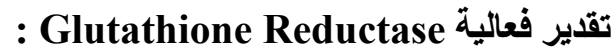

استخدمت طريقة Racker [13] لتقدير فعالية الإنزيم في حجم نهائي مقداره 1 مليلتر ويحتوي خليط التفاعل

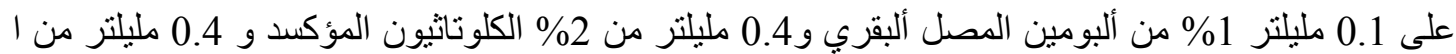

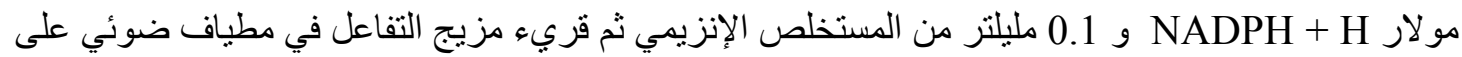

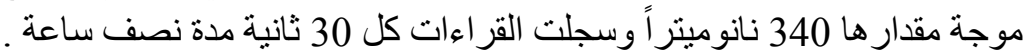

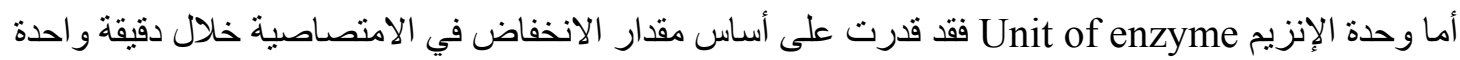

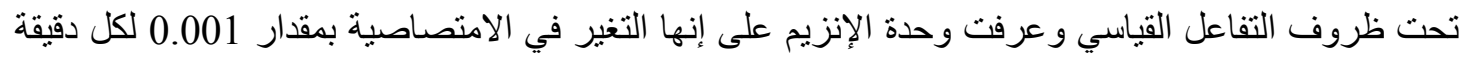

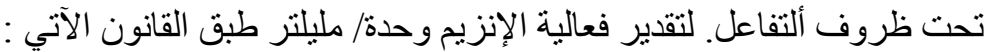

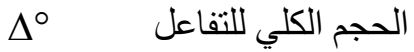

$\mathrm{T} 2-\mathrm{T} 1$

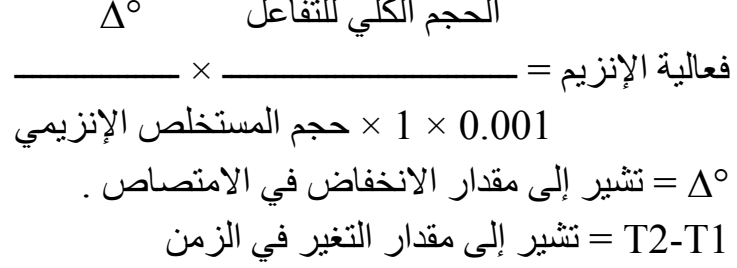




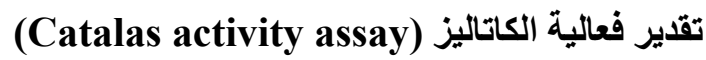

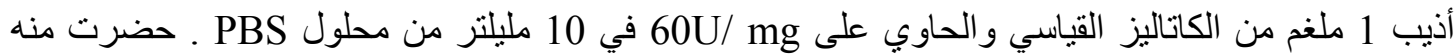
سلسلة من التر اكيز (U/ ml (0.6, 0.3, 0.15, 0.075, 0.0375) ، وذللك لغرض الحصول على منحني قياسي

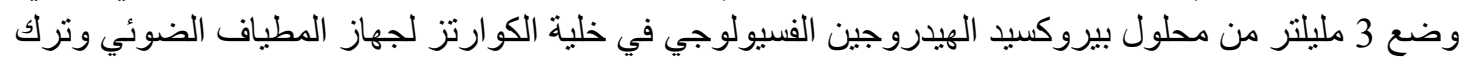
في الجهاز مدة 3 دقائق لغرض الاستقرار ـ أضيف بعدها 0.1 مليلتر من الكاتاليز القياسي او النموذج ومزج في

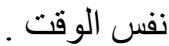

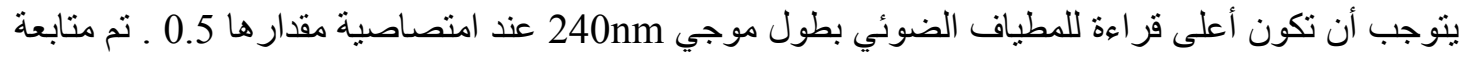
الانحدار في الامتصاصبة لكل 20 ثانية ، وقد كانت أول قراءة عند 10 ثو اني من إضافة الإنزيم بعد ذللك تكون

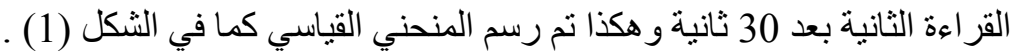

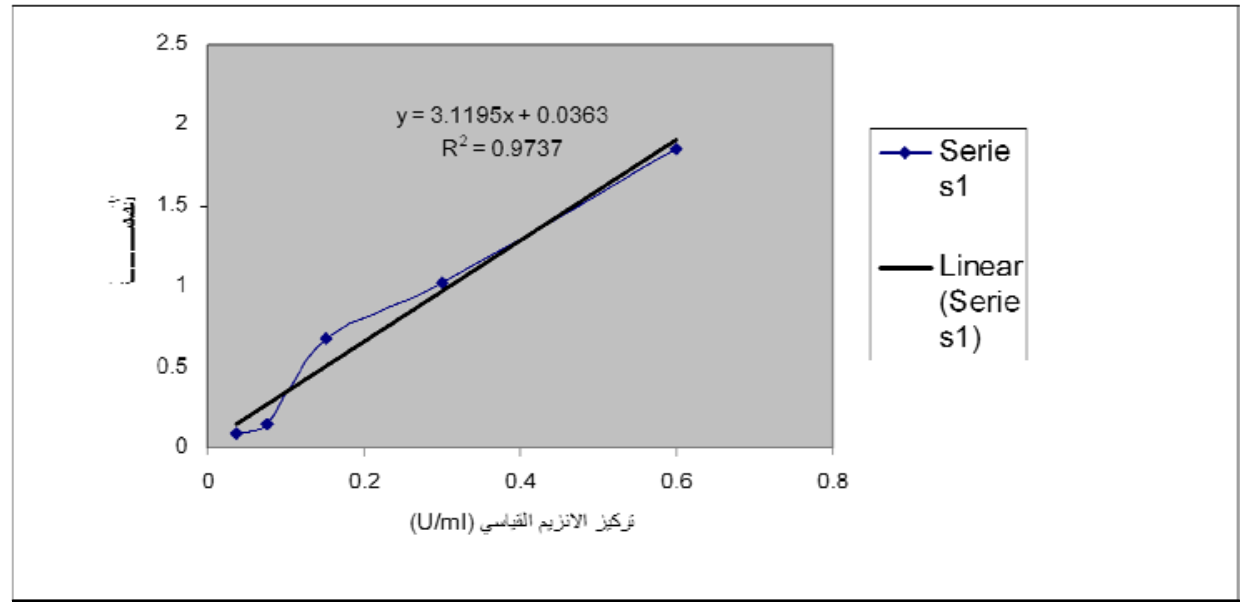

شكل (1): العلاقة بين تركيز انزيم الكاتاليز القياسي والامتصاصية لجهاز المطياف الضوئي (UV- spectrophotometer).

أما الفعالية النوعية Specific activity فانها تعبر عن عدد وحدات الإنزيم لكل ملغم \بروتين في المستخلص الإنزيمي وقد استخدمت طريقة Biuret [14] لتقدير كمية البروتين فالفعالية النوعية للإنزيم تمثل مقدار

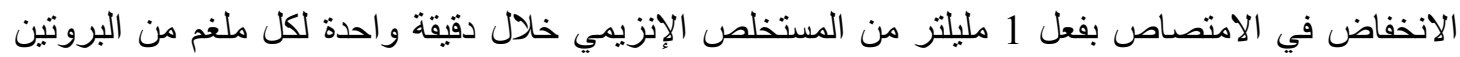

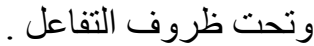

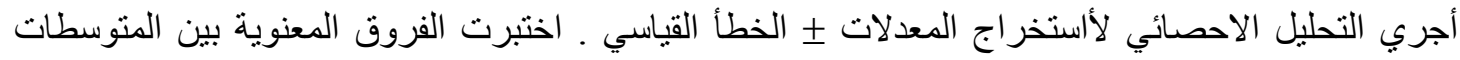
باستعمال اختباردانكن متعدد الحدود ، و لاختبار الفروق بين المتوسطات في تجارب التداخل التل للمقارنة بين المعاملة

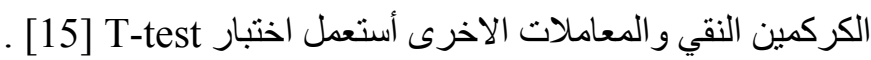

النتائج والمناقشة الفئة

\section{انتخاب التركيز الامثل للكركمين النقي للفعالية المضادة للأكسدة}

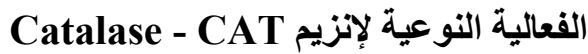

بينت النتائج في جدول (1) عند معاملة السيطرة الموجبة بالمركب CCl4 أدت إلى انخفاض معنوي لمستوى

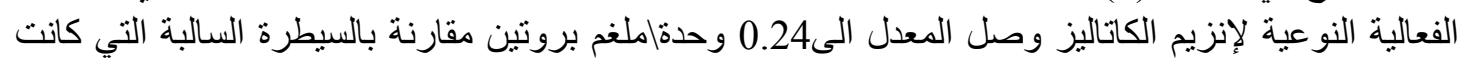

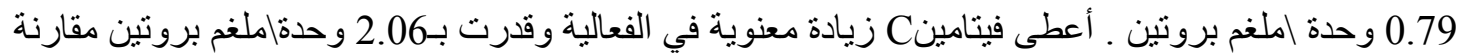

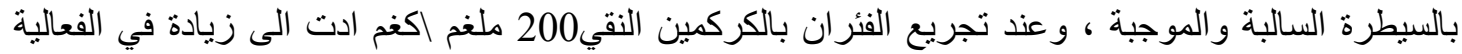

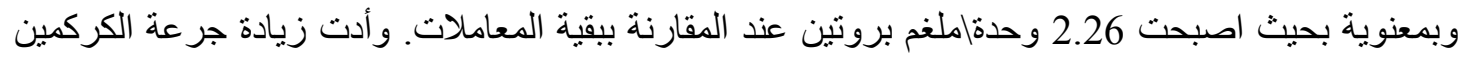

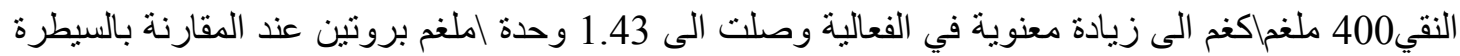

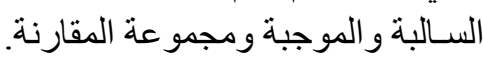

Glutathione Reductase- GR الفعالية النوعية لإنزيم النية

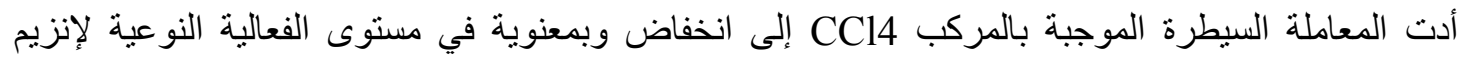
Glutathione reductase وحدة|ملغم بروتين، وقد أعطى فيتامينC زيادة في الفعالية بحيث اصبحت

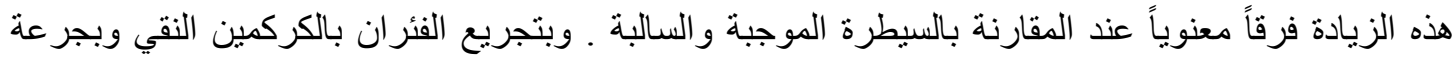


200 ملغم اكغم أزدادت الفعالية زيادة معنوية بحيث أصبحت 56.99 وحدة|ملغم بروتين مقارنة بالسبطرة السالبة

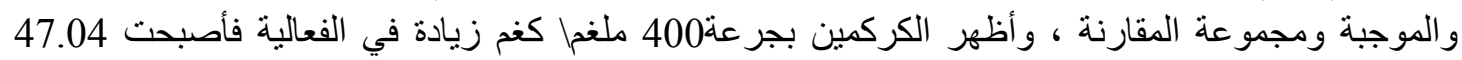

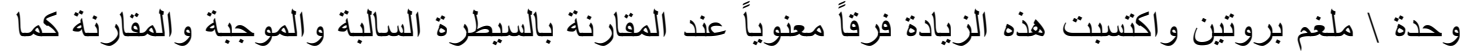

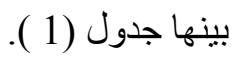

جدول ( 1) :يوضح معدلات نتائج فحوصات تضاد الأكسدة للمعاملات المختلفة لمدة سبعة ايام.

\begin{tabular}{|c|c|c|c|c|c|}
\hline الكركمين النقي & الكركمين النقي & السيطرة الموجبة & مجموعة|المقارنة [ & السيطرة السالبة & \multirow[t]{3}{*}{ المعاملة } \\
\hline [بجر عة400 & [بجرعة 200 & CCl4] بجرعة CCl] & فيتامين & \multirow[t]{2}{*}{ [الماء المقطر] } & \\
\hline ملفم اكفم ] مل & 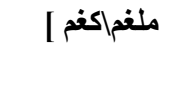 & 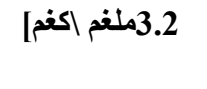 & بجرعة 180ملفم| & & \\
\hline \multicolumn{5}{|c|}{ المعدل الخطأ القياسي (وحدة|ملغم بروتين) } & الفحص \\
\hline${ }^{c} 0.06 \pm 1.43$ & a $\quad 2.26 \pm 0.03$ & ${ }^{\mathrm{E}} 0.24 \pm 0.01$ & ${ }^{b} 0.06 \pm 2.06$ & d $0.01 \pm 0.79$ & Catalase \\
\hline${ }^{c} 0.55 \pm 47.04$ & a $0.29 \pm 56.99$ & ${ }^{\mathrm{E}} 0.19 \pm 10.23$ & ${ }^{\mathrm{b}} 0.24 \pm 52.94$ & d $0.12 \pm 28.99$ & $\begin{array}{c}\text { Glutathione } \\
\text { Reductase }\end{array}$ \\
\hline
\end{tabular}

المعدلات التي تحمل حروف مختلفة ضمن الصف الواحل تختلف معنوياً .

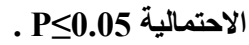

المعدلات لاثنتي عشرة مكررات

اظهر الكركمين النقي بجر عة 200 ملغم| كغم زيادة معنوية لفعالية المضادة للأكسدة من خلال زيادة المحتوى

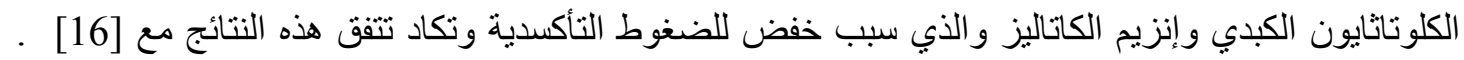

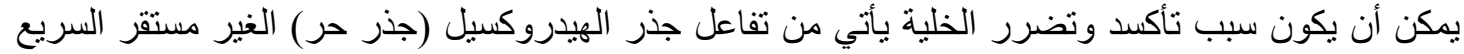

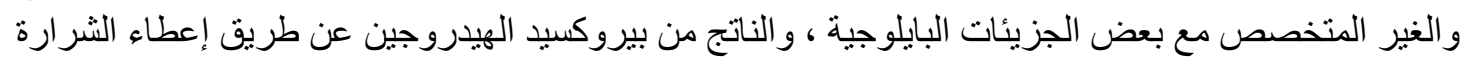

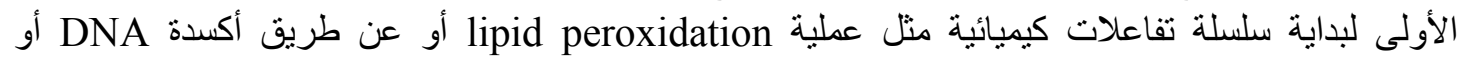
البروتين ، وان تضرر ألـ DNA سوف يسبب الطفرات ومن المحتمل يسبب السرطان إذا ما لم تتجح ميكانيكيات

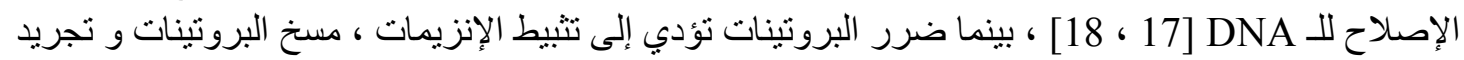

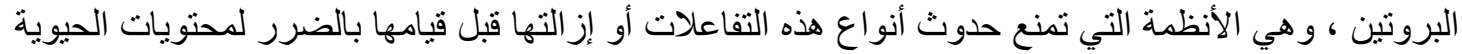

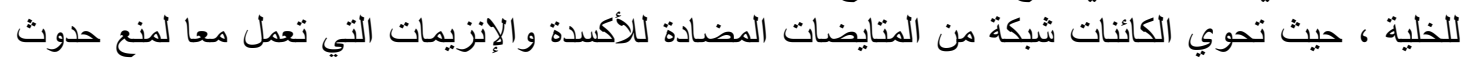

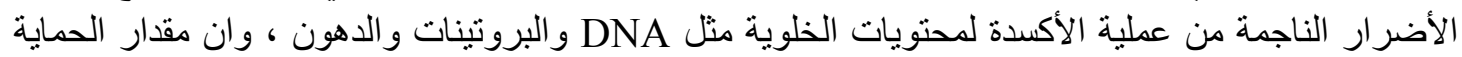

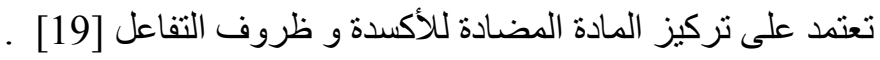

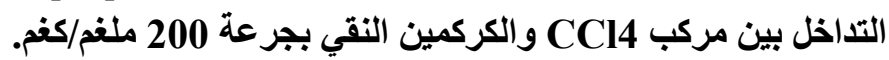
بعد أن نم التأكد من انعدام التأثيرات التاكسدية للجرعة المثنلى للكركمين النقي بالاعتماد على نتائج اختبارات

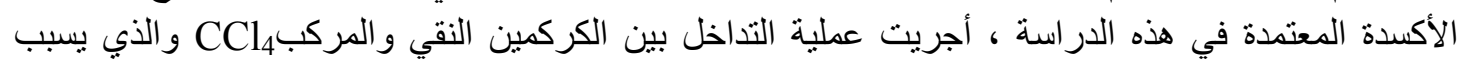

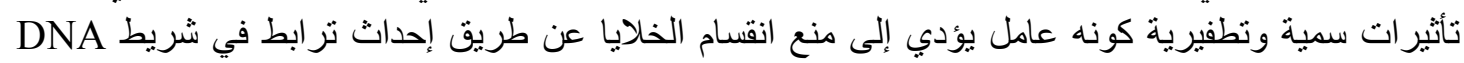

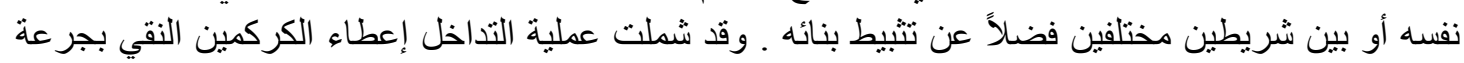

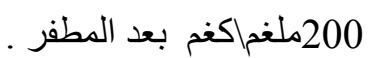

الفعالية النوعية لإنزيم Catalas- CAT

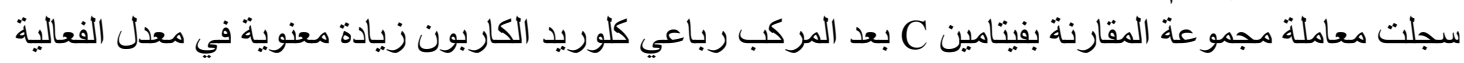

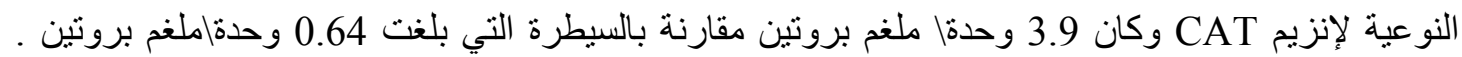

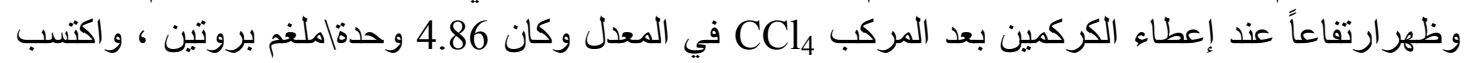

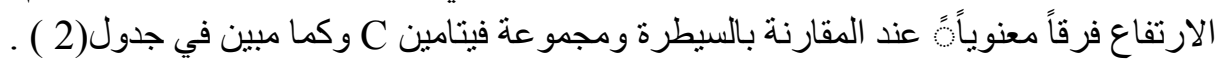

الفعالية النوعية لإنزيم Glutathione Reductase- GR

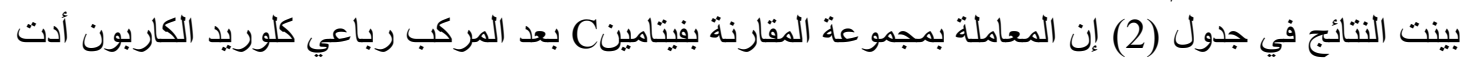

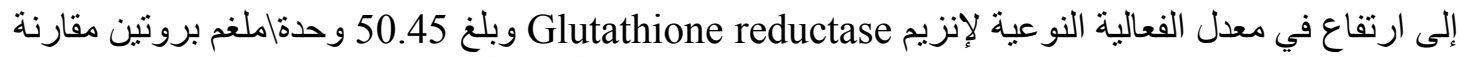

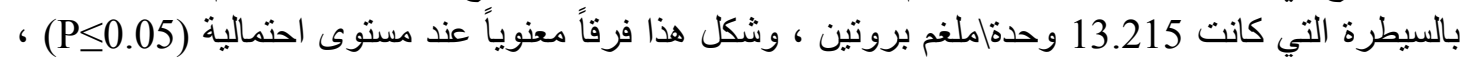

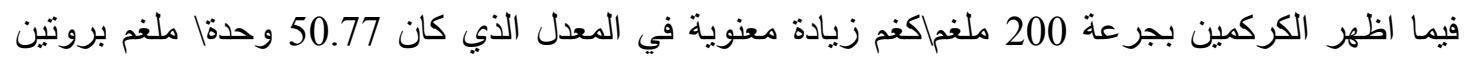

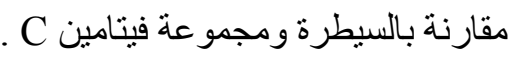


2010

\begin{tabular}{|c|c|c|c|}
\hline \multicolumn{4}{|c|}{ جدول (2) : يوضح معدلات نتائج فحوصات تضاد الاكسدةً للمعامله تداخل مع المركب4 CCl لمدةً سبعه ايام. } \\
\hline [مركب4 CCl +الكركمين & ] 180C مركب+CCl+فبتامين] & ] [ الماء المقطر]+CCl & \\
\hline النقي200 ملفم| كفم] & 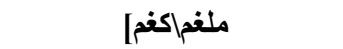 & & 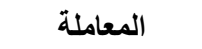 \\
\hline \multicolumn{4}{|c|}{ المعدلد الخطأ القياسي (وحدة|ملفم بروتين) } \\
\hline a $0.92 \pm 4.86$ & $0.3 \pm 3.9$ & $0.04 \pm 0.64$ & Catalase \\
\hline${ }^{\mathrm{b}} 0.89 \pm \mathbf{5 0 . 7 7}$ & a $1.07 \pm 50.45$ & ${ }^{c} 0.638 \pm 13.215$ & Glutathione \\
\hline & & & Reductase \\
\hline
\end{tabular}

المعدلات التي تحمل حروف مختلفة ضمن الصف الواحد تختلف معنوياً .

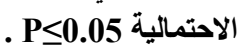

معدلات ست مكررات

ويتبين من نتائج هذا الاختبار أن للكركمين النقي تأثير فعال في خفض الضغط التأكسدي وحماية الخلايا من تأثير

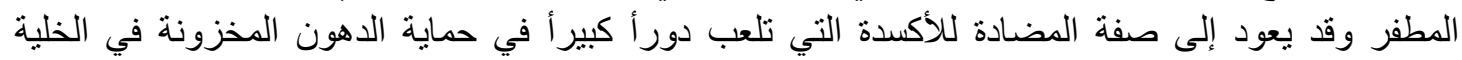

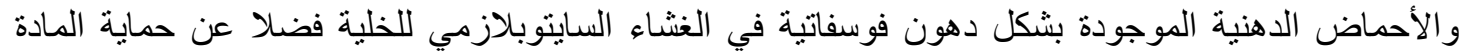

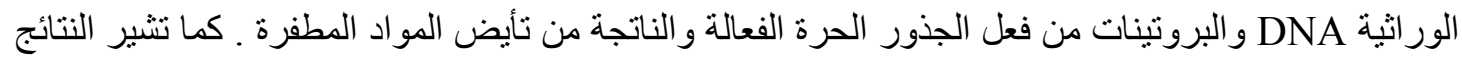

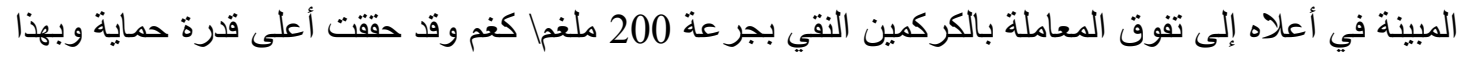

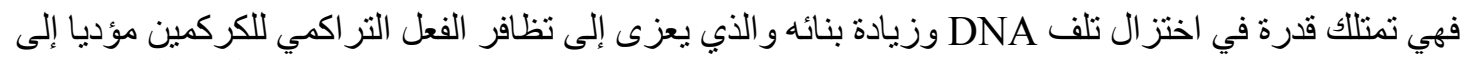

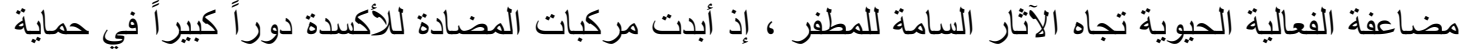

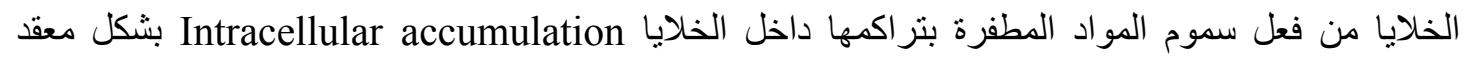

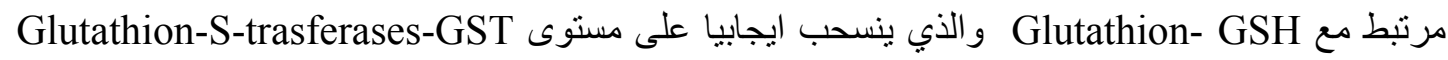
II enzymes داخل الخلايا وان درجة التر اكم داخل الخلايا مرتبط بقدرتها على تحفيز الطور الانزيمي الثاني phase بالمستخلصات نوفر وقتاً لتهيئة الجسم للحد من الآثار السمية للمطفر بتنشيط الإنزيمات المزيلة للسمية أو العمل

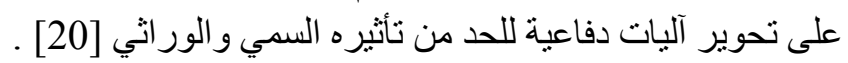

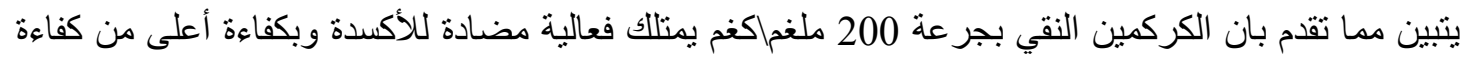

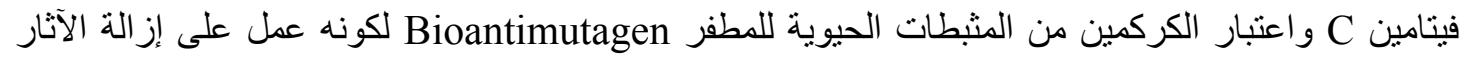

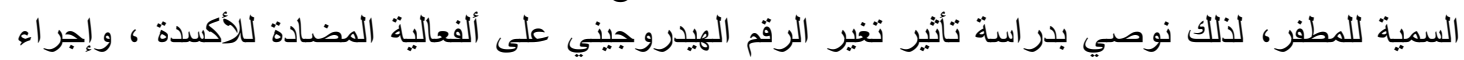

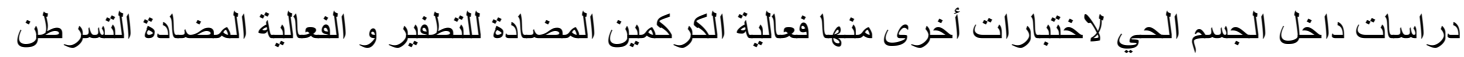

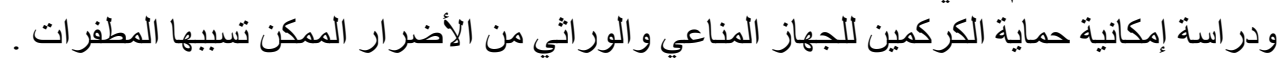

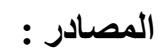

1. Valko, M.; Leibfritz, D.; MOucoi, J.; Cronin, M. and Telser, J. (2007) Free radicals and antioxidants in normal physiological functions and human disease. Int. J Biochem. Cell Biol., 39: 44-84.

2. Nunomura, A.; Castellani, R.; Zhu, X.; Moreira, P.; Perry, G. and Smith, M. (2006) Involvement of oxidative stress in Alzheimer disease. J Neuropathol Exp Neurol., 65: 631-641.

3. Wood-Kaczmar, A.; Gandhi, S. and Wood, N. (2006). Understanding the molecular causes of Parkinson's disease. Trends Mol Med 12: 521-8.

4. Davì, G.; Falco, A. and Patrono, C. (2005). Lipid peroxidation in diabetes mellitus. Antioxid Redox Signal 7: 256-268.

5. Hitchon, C. and El-Gabalawy, H. (2004). Oxidation in rheumatoid arthritis. Arthritis Res Ther., 6: 265-278. 
6. Cookson, M. \& Shaw, P. (1999). Oxidative stress and motor neurone disease. Brain Pathol., 9: 165-186.

7. Bjelakovic, G.; Nikolova, D.; Gluud, LL.; Simonetti, RG. and Gluud, C. (2008) Antioxidant supplements for prevention of mortality in healthy participants and patients with various diseases. Cochrane Database of Systematic Reviews (2) .

8. Bjelakovic, G.; Nagorni, A.; Nikolova, D.; Simonetti, R.; Bjelakovic, M. and Gluud C. (2006). Meta-analysis: antioxidant supplements for primary and secondary prevention of colorectal adenoma. Aliment Pharmacol. Ther., 24: 281291.

9. Tsuda, H.; Ohshima, Y.; Nomoto, H.; Fujita, K.; Matsuda, E.; Iigo, M.; Takasuka, N.; Moore, M.A. (2004) . Cancer prevention by natural compounds. Drug Metab. Pharmacokinet., 19: 245-263

10. Heath, DD.; Khwaja F. and Rock, CL. (2004) Curcumin content of turmeric and curry powders. J. FASEB, 18: A125.

11. Aggarwal, BB.; Kumar, A. and Bharti, AC. (2003) Anticancer potential of Curcumin: preclinical and clinical studies. Anticancer Res., 23:363-398.

12. Hudson, L. and Hay, F.C. (1980) Practical Immunology $2^{\text {nd }}$ Edition. Black Well Scientific Publ.: London.

13. Racker, E. (1955) Method in Enzymology. Vol. II (127) : 722-725.

14. Annino, J. (1964). Clinical chemistry principles and procedures Third Edition. Little, Brown and Company. Boston. PP: 186-187.

15. Duncan, D. B.(1955). Multiple range and multiple t- test biometrics, 11: 1-42.

16. Steele, VE.; Hawk, ET.; Viner, JL. and Lubet, RA. (2003) Mechanisms and applications of non-steroidal anti-inflammatory drugs in the chemoprevention of cancer. Mutat Res. 137: 523-524.

17. Sanchenz, JJ.; Monaghan, G.;Borsting, C.; Norbuy, G.; Morling, G. and Gaspar, HB. (2007) Carrier frequency of anon sense mutation in the adenosine deaminase (ADA) gene implies a high incidence of ADA-dafinicient severe combined immunodeficiency [SCID] in Somalia and sigle, Common haplotype indicates common an cestry. Ann. Hum. Genet., 71:336-347.

18. Nakabeppu, Y.; Sakumi, K.; Sakamoto, K.; Tsuchimoto, D.; Tsuzuki, T. and Nakatsu, Y. (2006) Mutagenesis and carcinogenesis caused by the oxidation of nucleic acids. Biol Chem., 387: 373 -379.

19. Vertuani,s.;Angusti, A. and Monfredini, S. (2004)The antioxidants and proantioxidants network; an overview. Curr. Pharm. Des.,10: 1677-1694.

20. Kuroda,Y. and Hara, Y. (1999) Antimutagenic and anticarcinogenic activity of tea polyphenols. Mut. Res., 436: 69-97. 